\title{
Plantar sensory threshold in the ulcerative foot
}

\author{
J A BIRKE \& D S SIMS \\ Physical Therapy Department, National Hansen's Disease Center, \\ Carville, Louisiana 70721, USA
}

Accepted for publication 28 January 1986

\begin{abstract}
Summary Pressure threshold measurements were made using a set of three Semmes-Weinstein monofilaments on 132 plantar ulcer sites in 72 leprosy patients and 45 plantar ulcer sites in 28 diabetic patients. The most common sites of ulceration were the great toe and first metatarsal head. No patient could feel monofilaments smaller than $6 \cdot 10(75 \mathrm{~g})$. The next smallest filament, 5.07 $(10 \mathrm{~g})$, was identified as the level of protective sensation in leprosy patients who customarily use footwear. Similar results were shown in a small group of diabetic patients.
\end{abstract}

\section{Introduction}

Plantar foot ulcers are well recognized as a major cause of disability in leprosy and diabetes mellitus. Residual neuropathy may result in episodes of ulceration and progressive deformity even when leprosy is cured and diabetes is controlled. Sensory loss and local pressure have been shown to be the cause of plantar ulceration in leprosy and the most common cause in diabetes. ${ }^{1-5}$ Reliable clinical methods of measuring sensation are extremely important in the prevention of foot ulcers.

The relationship between sensory loss and the risk of plantar ulceration has been studied by several investigators. One study found a significant association between the presence of an ulcer and the degree of sensation to pinprick in the feet of leprosy patients. ${ }^{4}$ Another study using Von Frey aesthesiometers found higher pressure thresholds in the feet of diabetic patients compared to normal controls. ${ }^{6}$ A further study using vibration perception found elevated sensory thresholds were associated with a history of plantar ulceration in diabetic patients. ${ }^{7}$ There is general agreement among these investigators that impaired sensation may lead to frequent foot injuries but the degree of sensory loss required for a patient to be at risk of plantar ulceration has not been determined. 
Protective sensation is a well accepted term in recent literature. ${ }^{1,8-10}$ Despite common use of this term, few investigators have provided a precise definition of protective sensation. Von Prince identified a level of protective sensation in the hand using Semmes-Weinstein monofilaments based on concomitant loss of the ability to feel heat or pinprick. The World Health Organization (WHO) Expert Committee on Leprosy in 1970 recommended testing for loss of protective sensation by touching the point of a pencil to the patient's skin with enough force to cause dimpling. Blindfolded, the patient must localize the point touched within $2 \mathrm{~cm}$. This method is limited by the inability to standardize the stress applied to the skin by a pencil point. Brand recommended that protective sensation be defined by an individual's actual susceptibility to injury rather than arbitrary criteria. No investigators have established a level of protective sensation based on incidence of injury in the foot for a group of patients with leprosy.

Pressure threshold assessment is an ideal modality for testing patients at risk of ulceration, since unperceived pressure is the mechanism of injury in the foot, ${ }^{3}$ and nylon monofilaments can be manufactured inexpensively for use by field workers in developing countries. Graded, pressure sensitive filaments have been recommended for objectively evaluating sensory function in leprosy. ${ }^{11-13}$ This method was first described by Von Frey and later Semmes and Weinstein developed a set of 20 nylon monofilaments of standardized lengths and thicknesses. ${ }^{14}$ These filaments buckle at a reproducible stress and may be identified by the manufacturer's numbers ranging from 1.65 to 6.65 (common logarithm of 10 times the monofilament buckling force in milligrams) or the measured force in grams. We have previously identified the Semmes-Weinstein 4.17 filament as the mean plantar threshold plus two standard deviations for normals and found filaments $4 \cdot 17(1 \mathrm{~g}), 5 \cdot 07(10 \mathrm{~g})$ and $6 \cdot 10(75 \mathrm{~g})$ to be a reliable set of test instruments at the $95 \%$ confidence interval (study submitted for publication).

Several investigators have compared the sensitivity of vibrometry, SemmesWeinstein filaments, $256 \mathrm{hz}$ tuning fork, two point discrimination, pinprick, and light touch. Vibrometry and Semmes-Weinstein monofilaments were found to be the most effective methods of measuring sensory deficits in the hand and foot. ${ }^{15,16}$ Threshold tests (vibrometry and Semmes-Weinstein filaments) are more likely to show gradual and progressive change seen in chronic neuropathy and compression syndromes as compared to innervation density tests (two-point and moving two-point discrimination). ${ }^{15,17}$ Innervation density tests require greater cortical integration which results in these tests being less sensitive to loss of sensory axons.

\section{Purpose}

There is an absence of data to identify a threshold of protective sensation on the plantar surface of the foot. Such data would enable preventative foot pro- 
grammes to focus on those patients at highest risk of foot ulceration. The purpose of this study was to determine sensory thresholds for the feet of patients with a history of plantar ulceration and identify a level of protective sensation for the foot in leprosy.

\section{Method}

Testing was performed on all leprosy and diabetic patients seen by the Physical Therapy Department at the National Hansen's Disease Center with the presence or history of plantar ulceration during a one-year period, 1984-85. Seventy-two leprosy and 28 diabetic male and female patients were included in this study. Sites of ulceration were determined by physical examination, medical records and patient interview. Questionable sites were not included in the study. SemmesWeinstein filaments* 4.17, 5.07 and 6.10 were used for pressure threshold measurements. All filaments were calibrated on an Arbor 107 analytical balance. $\dagger$ The sensory testing technique used was similar to that described by Bell. ${ }^{18}$ Patients were tested in a quiet area and filaments were applied in ascending order perpendicular to the skin at an approximate rate of $1 \mathrm{~s}$ touch, $1 \mathrm{~s}$ hold and $1 \mathrm{~s} \mathrm{lift}$. The patient responded yes when a touch was perceived. Testing was performed on the skin along the perimeter of the ulcer site to avoid testing of scar, callous or necrotic tissue. The site of ulceration and sensory level perceived was recorded on a foot screening form. Additional preselected areas of the foot were also tested and recorded on the form. An integer scale was used to code pressure thresholds in order to simplify the recording method (Table 1).

\section{Results}

\section{LEPROSY PATIENTS}

The mean age of the Hansen's disease patients was $57 \cdot 4( \pm 17 \cdot 2)$ years. Pressure thresholds were determined on a total of 132 ulcer areas (Table 2). No area received a rating less than three. Fourteen per cent were rated three, and the

Table 1. Pressure threshold scale.

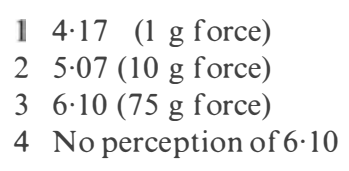

Suppliers

* Nylon filament material, Irving Reicht, D Ontario Street, Philadelphia, PA 19134.

† Arbor 107 Analytical Balance, Arbor Laboratories, 3784 Fabian Way, Palo Alto, CA 94303. 
Table 2. Ulcer frequency and pressure thresholds: leprosy patients.

\begin{tabular}{cccccc}
\hline Total & Total & Subjects & \multicolumn{3}{c}{ Pressure threshold } \\
subjects & ulcers & $>1$ ulcer & $<610$ & $6 \cdot 10$ & $>6 \cdot 10$ \\
\hline 72 & 132 & 33 & 0 & 19 & 113 \\
\hline
\end{tabular}

remaining $86 \%$ were rated four. Figure 1 shows the distribution of ulcers by anatomical site in the leprosy patients. The plantar surface of the great toe was the most common area of ulceration and the first metatarsal head was the second most common site.

\section{DIABETIC PATIENTS}

The mean age of the diabetic subjects was $51 \cdot 1( \pm 11 \cdot 1)$ years. Pressure thresholds were determined on 45 ulcer areas (Table 3). No area received a rating less than

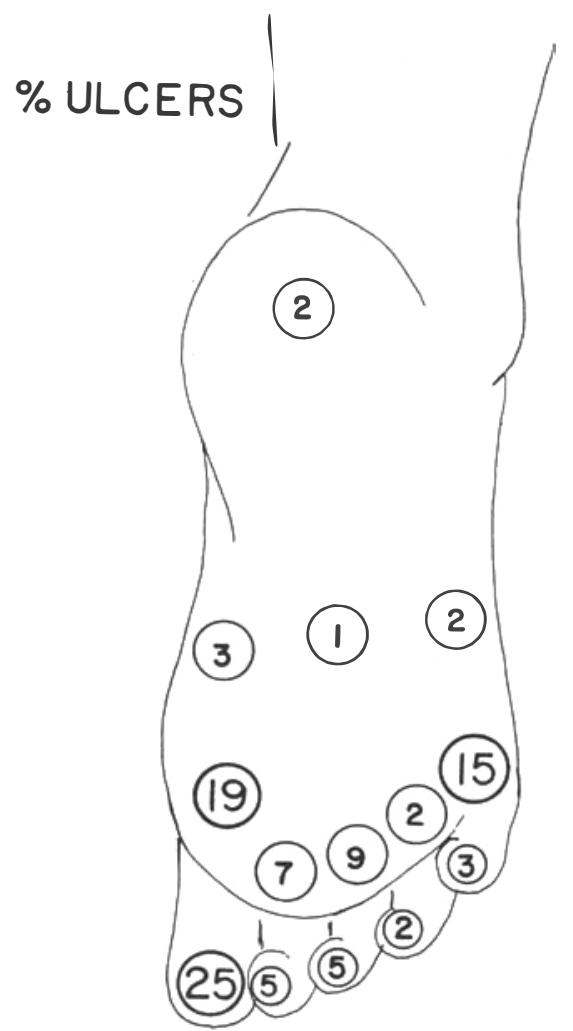

Figure 1. Plantar ulcer distribution in leprosy. 
Table 3. Ulcer frequency and pressure thresholds: diabetic patients.

\begin{tabular}{cccccc}
$\begin{array}{c}\text { Total } \\
\text { subjects }\end{array}$ & $\begin{array}{c}\text { Total } \\
\text { ulcers }\end{array}$ & $\begin{array}{c}\text { Subjects } \\
>1 \text { ulcer }\end{array}$ & \multicolumn{3}{c}{ Pressure threshold } \\
$<6 \cdot 10$ & $6 \cdot 10$ & $>6 \cdot 10$ \\
\hline 28 & 45 & 15 & 0 & 4 & 41 \\
\hline
\end{tabular}

three. Nine per cent were rated three, and the remaining $91 \%$ were rated four. The most common area of ulceration was the first metatarsal head $(35 \%)$ and the second most common site was the great toe $(24 \%)$.

\section{Discussion}

The distribution of plantar ulcer sites in this study was similar to that found by Ctercteko ${ }^{5}$ and Sabato. ${ }^{4}$ They found the most common sites of ulceration to be the first metatarsal head and great toe. In this study the great toe was the most frequently ulcerated area in the leprosy group, and the first metatarsal head was the most common site in the diabetic group.

Plantar sensory thresholds were measured in this investigation in a group of patients with known foot injuries (ulcerations). Pressure testing instruments used in this study were previously shown to be sensitive and reliable in evaluating chronic neuropathy in the hand and foot. The lowest threshold of pressure sensation surrounding an ulcer area was found to be the Semmes-Weinstein 6.10 filament. A logical choice for testing protective sensation was the next lowest filament, 5.07. We believe that patients who can perceive this level of pressure sensation are unlikely to sustain major foot injuries. A prospective study is planned to investigate further the validity of this definition of protective sensation.

The possibility that sensory loss is a result rather than a cause of ulceration must be considered in this investigation. If nerve damage were to occur secondary to ulceration the distribution of sensory loss would be limited to the area of the ulcer. Patients tested in this study had diffuse patterns of sensory loss on the bottom of the foot indicative of tibial nerve trunk involvement. This evidence suggested that the sensory loss preceded plantar ulceration.

All patients in this study were accustomed to wearing footwear on a regular basis during walking. Barefoot walking results in hypertrophy of the plantar soft tissues and may alter the threshold of pressure sensation. Patients in countries where barefoot walking is common practice may demonstrate higher normal and protective thresholds when tested with similar instruments. ${ }^{19}$ Evaluation of our procedures is needed by leprosy control programmes in other countries. 
The sample of diabetic ulcers presented is from a small group of patients referred to the centre with severe foot problems and may not be representative of diabetic plantar foot ulcers in the general population. Further study is needed to determine if a similar protective sensory level is found in a large population of diabetic patients.

\section{Conclusions}

Within the limitations of this study it is possible to conclude the following:

1 The lowest pressure threshold of leprosy patients and a small sample of diabetic patients with a history of plantar ulceration was Semmes-Weinstein filament $6 \cdot 10$.

2 Semmes-Weinstein filament 5.07 was identified as the level of protective sensation in leprosy patients who customarily use footwear.

\section{References}

${ }^{1}$ Lang-Stevenson AI, Sharrard WJ, Betts RP, Duckworth T. Neuropathic ulcers of the foot. $J$ Bone Joint Surg (Br), 1985; 67B: 438-42.

${ }^{2}$ Brand PW. The insensitive foot. In: Jahss $\mathrm{M}$ ed. Disorders of the foot. Philadelphia: WB Saunders, 1982; 1266-86.

${ }^{3}$ Hall DC, Brand PW. The etiology of the neuropathic ulcer. J Am Podiaty Assoc, 1979; 69: 173-7.

${ }^{4}$ Sabato S, Yosipovitch Z, Simkin A, Sheskin J. Plantar trophic ulcers in patients with leprosy. Int Orthop, 1983: 24: 203-8.

${ }^{5}$ Ctercteko GC, Dhanendran M, Hutton WC, Le Quesne LP. Vertical forces acting on the feet of diabetic patients with neuropathic ulceration. Br J Surg, 1981; 68: 608-14.

${ }^{6}$ Chockinov RH, Ullyot GL, Moorhouse JA. Sensory perception relatives. N Engl J Med, 1972 286: 1233-62.

7 Boulton AJD, Hardisty CA, Betts RP, Franks CI, Worth RC, Ward JD, Duckworth T. Dynamic foot pressure and other studies as diagnostic and management aids in diabetic neuropathy. Diabetes Care, 1983; 6: 26-33.

${ }^{8}$ Brand PW. Clinical mechanics of the hand. St. Louis: C V Mosby, 1985; 186.

9 Von Prince K, Butler B. Measuring sensory function of the hand in peripheral nerve injuries. Am J Occup Ther, 1967; 6: 385-95.

10 World Health Organization. A guide to leprosy control. Geneva, 1980; 77-81.

11 Pearson JM. The evaluation of nerve damage in leprosy. Lepr Rev, 1982; 53: 119-30.

12 Naafs B, Dagne T. Sensory testing: a sensitive method in the follow-up of nerve involvement. Int $J$ Lepr, 1977; 45: 364-68.

13 Jamison DG. Sensitivity testing as a means of differentiating the various forms of leprosy found in Nigeria. Int J Lepr, 1971; 39: 504-7.

14 Levin S, Pearsall G, Ruderman RJ. Von Frey's method of measuring pressure sensibility in the hand: an engineering analysis of the Weinstein-Semmes pressure aesthesiometer. Hand Surg, 1978; 3: 211-16.

15 Szabo RM, Dimick MP. Sensibility testing in patients with carpal tunnel syndrome. J Bone Joint Surg, (Am), 1984; 66A: 60-4. 
16 Weise MD, Garfin SR, Gelberman RH, Katz MM, Thorne RP. Lower-extremity sensibility testing in patients with herniated lumbar intervertebral discs. J Bone Joint Surg (Am), 1985; 67A: 1219-24.

17 Gelberman RH, Szabo RM, Williamson RV, Dimick MP. Sensibility testing in peripheral nerve compression syndromes: an experimental study in humans. J Bone Joint Surg (Am), 1983; 65A: 632-8.

${ }^{18}$ Hunter JM, Schneider LH, Mackin EJ, Bell JA. Rehabilitation of the hand, St. Louis: C V Mosby, 1978: 273-G1.

19 Weddell G, Jamison D, Palmer E. Recent investigations into the sensory and neurohistological changes in leprosy. In: Cochrane RG ed. Leprosy in theory and practice. Bristol: John Wright and Sons, 1959; 101. 